\title{
Underwater Pile Driving Hammer with Active Impact Body
}

\author{
Petar Bodurov ${ }^{1} \&$ Vasil Genchev ${ }^{1}$ \\ ${ }^{1}$ Company BILBORD AD, 1463 NDK, 1 "Bulgaria" Square, ent. AI. 4, Sofia, Bulgaria \\ Correspondence: Vasil Genchev, ${ }^{1}$ Company BILBORD AD, 1463 NDK, 1 "Bulgaria" Square, ent. AI. 4, Sofia, \\ Bulgaria. Tel: 359-888-962-989. E-mail: genchev@digitalprint.bg
}

Received: March 7, $2012 \quad$ Accepted: April 10, $2012 \quad$ Online Published: May 24, 2012
doi:10.5539/mer.v2n1p81
URL: http://dx.doi.org/10.5539/mer.v2n1p81

\begin{abstract}
Consider the hammer to drive the piles under water. In these hammers now used only rises mechanical percussion part and then it falls freely from some height on the drive pile.In the proposed structure of the shock it is driven in the fall on the pilot, ie it is an active percussion part. Moreover, the impact of the hammer does not move in the sealed housing and is in direct contact with the aquatic environment. This solution simplifies the construction of the hammer and makes it suitable for work in all depths. Running the percussion part - in rising and falling, is done by rocket engines. In general it can be used almost all types of rocket engines, but the authors are most appropriate electric rocket engines using for working body the overlying water. Of electric rocket engines are emerging as favorite laser because they seamlessly provide instant water heating in rocket chambers with temperatures of 4,000 to $10,000{ }^{\circ} \mathrm{C}$ and its evaporation. Thus, the proposed hammer will have very simple structure in which only one moving part - the striking part and the supply of electrical energy will be only one wire. Here are the velocities and displacements of the four variants of the mass of the percussion part. These are the advantages of the proposed hammer to drive the piles under water - all possible depths.
\end{abstract}

Keywords: underwater pile driving hammer, impact body (Ram), rocket engine

\section{Introduction}

The subject of the article is an underwater pile driving hammer(PDH) with an active impact body (Ram) which is used for driving piles on ocean, sea, lake or river floors (Bodurov \& Genchev, 2011). Its largest application is in driving piles for anchoring petrol platforms at very big depths which are inaccessible by the existing anchoring equipment. Another possible application of this hammer is in anchoring floating offshore platforms with wind turbines.

The ultimate possibilities of today's underwater pile hammers are to drive a pile which is a steel pipe with an outer diameter of $2 \mathrm{~m}$, a length of $100 \mathrm{~m}$ and a mass about $400000 \mathrm{~kg}$, at the ocean floor having a depth of not more than $3000 \mathrm{~m}$. A safety anchoring of a petrol platform is possible by driving up to 6 such piles having in mind that to drive one pile you need up to 5000 blows by a hammer Ram with a mass not less than $20000 \mathrm{~kg}$.

The Ram of the existing hammers rises to the initial position by hydraulic cylinders and strikes at a speed of not more than $6 \mathrm{~m} / \mathrm{s}$, starting a free fall in a hermetic body where a high pressure air environment is maintained (MENCK, 1994). This scheme is very expensive and complicated for realization and operation; in addition it is hardly feasible at depths greater than $3000 \mathrm{~m}$ and limits the blow rate of the Ram as well as its mass. Besides, the piles are only driven vertically. There also exists a risk of environmental pollution due to possible accidents with the hydraulic equipment used.

\section{Functional Flowchart of PDH}

The design of PDH proposed (Bodurov \& Genchev, 2011) does not require complicated and expensive hermetization of the Ram during its motion. Surrounding water totally embraces the elements of the hammer, so it can operate without any problem even at greatest depths. Rocket engines are used for actuating the Ram (Bodurov, 1978; Bodurov et al., 1999; Bodurov \& Penchev, 2005).

Pile driving history from 8000 years ago till today relates to driving with free falling Ram which can rise in various ways to a certain height and is left to fall from there. By 1839, when the Scottish inventor James Nasmyth devised the steam hammer, a mechanical pile driving began which is only focused on the power-actuated lifting of the Ram to a certain height. The very essence of driving did not change. Consecutively, 
the steam engine was replaced by a diesel engine and then by a hydraulic drive, whereas the Ram remained to be an element which fell free on the driven pile.

For the first time, we started to actuate the Ram during striking too, i.e., the driving hammer already has an active impact body (Ram). For this purpose, we fixed to the Ram a rocket engine, which was specially adapted for striking and enduring dynamic forces caused by the impact (Bodurov \& Penchev, 2005; Bodurov, 2008; Raketenantrieb für..., 2009). This kind of rocket engines are developed by us for actuating industrial machines, such as hammers, and that is why we have called them industrial rocket engines (IRE).

An industrial rocket engine model IRE-2 created especially for driving Ram of the pile driving hammers is shown on Figure 1-a. It is fed with kerosene as a fuel and compressed air as an oxidant which are passed through flexible hoses.

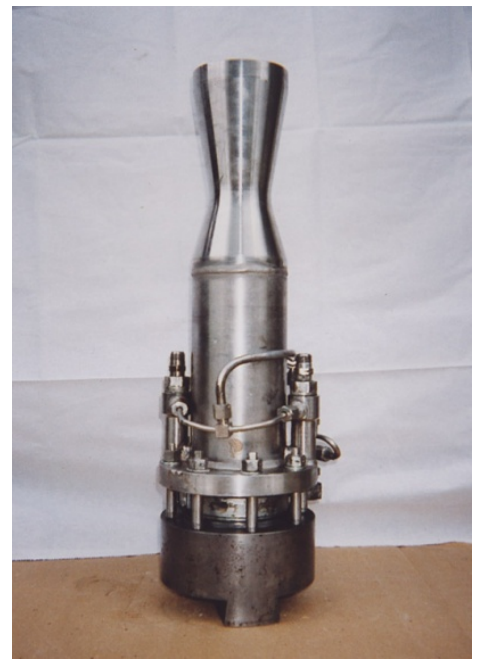

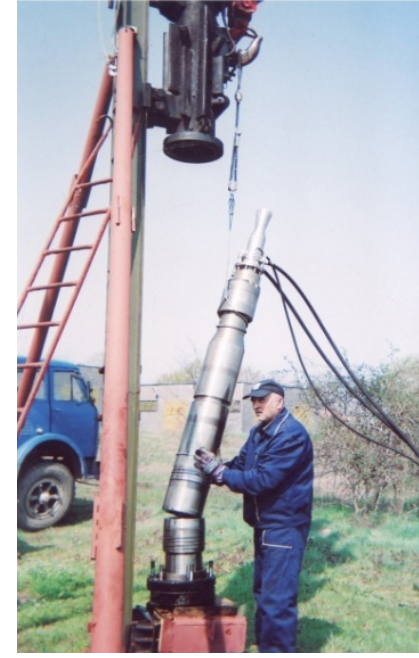

b

Figure 1. a - Industrial rocket engine, model IRE-2, with a traction up to $2000 \mathrm{~kg}$, designed for actuating diesel pile driving hammers with a falling part(Ram) to $2200 \mathrm{~kg}$, b - Assembling of IRE-2 to the Ram of a diesel pile driving hammer with a falling part of $500 \mathrm{~kg}$

The availability of an active Ram allows to drive piles at any angle without problems. In addition, it is possible to realize even greater speeds of the Ram without increasing the height of its fall. In this way, the PDH proposed is significantly different from the existing hammers by two reasons: 1) it is not hermetized, so that it can operate underwater at the same conditions as in the ground, and 2) its Ram is already active. The pile driving hammers stabbed in the ground can use existing mechanisms for raising the Ram such as steam, diesel or hydraulic engines, and the rocket engine is only used at accelerating the Ram when the pile is driven, whereas in the underwater pile driving hammers both movements of the Ram are only realized by rocket engines.

Depending on the various working depths and the necessary impact energies, different kinds of rocket engines chemical, catalytic, electrical, laser etc. will be used. The chemical rocket engines will only be applied in ecological variants which are mainly two. The first variant uses kerosene as a fuel and nitrogen acid as an oxidant which are fed on portions in the combustion chambers of the rocket engines where they are mixed, self-ignited and combusted, thus generating a reactive traction. The combustion products are harmless because in the process only water, nitrogen and carbon dioxide are released. The second variant uses liquefied hydrogen and oxigen. However, because of the fact that the liquefied hydrogen will make the operation more expensive and more complicated, a third variant is also possible, where an installation mounted to the hammer will produce gaseous hydrogen and oxigen from the surrounding water, which will be passed along flexible hoses in the chambers of the rocket engines. The catalytic rocket engines operate with only one component which will be broken down to gaseous products after contact with catalysts. A catalytic rocket engine recommended for underwater hammers uses the compound hydrogen peroxide, $\mathrm{H}_{2} \mathrm{O}_{2}$, as a working medium, which, after contacting a catalyst, for example manganese dioxide, $\mathrm{MnO}_{2}$, or platinum, $\mathrm{Pt}$, breaks down to gaseous water, 
$\mathrm{H}_{2} \mathrm{O}$, and oxigen - $\mathrm{O}$, which are totally nonpolluting.

Yet the usage of a chemical rocket engines and catalytic rocket engines requires the presence of tanks for fuel and oxidant, which will cause some difficulties when the hammers are stabbed at depths greater than $3000 \mathrm{~m}$. That is why we propose a more radical solution allowing to work at greater and practically any depths by using the water surrounding pile hammers as working media which, at its own, without the need of pump or other facilities, will fill the rocket chambers. During the subsequent heating and evaporating the water in the rocket chambers pushes out the remaining water through the chamber nozzle, thus generating rocket traction. The necessary electric energy for heating and evaporation of the water in the chambers will be supplied through a cable located on a ship above the hammer or through another energy source - e.g. from the ground by underwater cable. When the working media is heated and evaporated by laser, you can use also an optical conductor. The laser rocket engine is seen as extremely prospective since it ensures a trouble-free heating at temperatures from 4000 to $10000^{\circ} \mathrm{C}$. The electrical rocket engines are being developed for a long time and there is no trouble in their application for actuating industrial machines as well. The problem is that they are developed exclusively for spacecraft flights and this means that they are forced to conform with the shortage of working media and energy in the outer space. This is why these engines are developed to generate very small forces. In our case, for actuating of PDH in conditions of earth water basins, there is no problem to ensure the necessary electric energy as well as the availability of practically unlimited quantities of working media - the surrounding water environment.

The schematic structure of the hammer proposed is elucidated with a longitudinal section given on the Figure 2 (Bodurov \& Genchev, 2011). The hammer is dropped into the water by cords fixed to the ears 8 . The ears 8 are fastened to the frame 7. The base 2 is placed on the pile 1 . The Ram 6 moves along the guides 3 mounted on the base 2 . The frame 7 is also fixed immovably to the guides 3 . The rocket engines 4 and 9 are immovably fastened, by fixing elements 5 , to the Ram 6 . The rocket engines 4 serve to raise the Ram 6 bottom-up, and the rocket engines 9 are switched on when the Ram 6 falls down - driven top-down from its upper position till striking a blow on the upper part of the base 2 which serves as an anvil of the hammer. The cycle described is repeated until the pile 1 is totally driven.

A design of a pile driving hammer stabbed into the ground (Bodurov, 2008) is known where the raising of the Ram to the upper position is performed by a diesel engine, while the striking movement of the Ram is actuated by the rocket engine (Raketenantrieb für..., 2009) fixed immovably to it. However, all movements of the Ram in PDH - bottom-up and top-down - are realized by rocket engines. The chosen way of actuating the Ram by rocket engines makes the Ram independent from the environment - irrespectively whether the hammer will work in vacuum, in a liquid or in another medium.

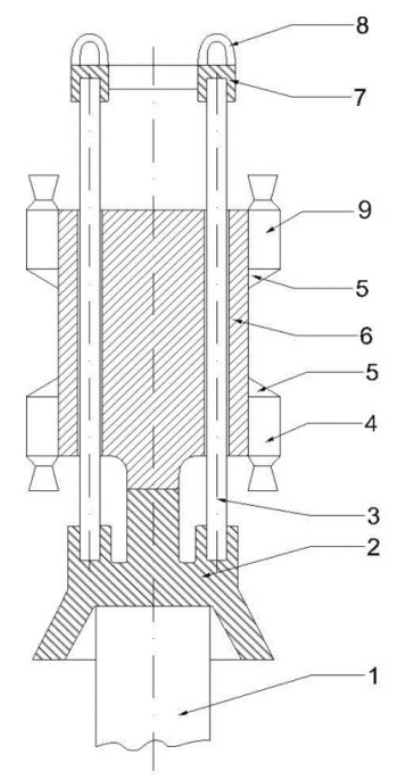

Figure 2. Schematic structure of an underwater pile driving hammer(PDH): 1 - pile, 2 - base, 3 - guides, 4 rocket engine, 5 - fixing element, 6 - impact body(Ram), 7 - frame, 8 - ears, 9 - rocket engine 


\section{Variants of PDH with Various Masses of the Ram}

Table 1 shows four model variants for the mass $\mathrm{G}$ of the hammer impact body (Ram) - stabbed in the ground and underwater, as well as the traction $\mathrm{R}$ necessary for its moving bottom-up to reaching the upper, i.e. initial position, and top-down for striking a blow. The traction $\mathrm{R}$ for realization a trouble-free raising of the Ram underwater should be greater than the mass $\mathrm{G}$ by not less than $20 \%$. We accepted that this increase shall be $25 \%$. All the four variants are foreseen for generating the same impact energy. In this way, it is easier to choose specific parameters. In order to simplify the calculations, we examined some examples where the traction of the rocket engines bringing back the Ram in the upper or initial position after striking is equal to the traction of the rocket engines accelerating the Ram when it falls and drives a pile. We suppose that in some cases it is more favorable that both types of engines - for moving the Ram up and for its moving down - have different tractions as well as that their tractions are adjustable - stepwise or stepless.

Table 1

\begin{tabular}{cccc}
\hline Variant No. & $\begin{array}{c}\mathrm{G} \text { (in the ground) } \\
{[\mathrm{kg}]}\end{array}$ & $\begin{array}{c}\mathrm{G} \text { (underwater) } \\
{[\mathrm{kg}]}\end{array}$ & $\begin{array}{c}\mathrm{R} \\
{[\mathrm{kg}]}\end{array}$ \\
\hline 1 & 30000 & 24000 & 30000 \\
2 & 21160 & 17630 & 22000 \\
3 & 16585 & 13500 & 16875 \\
4 & 13105 & 10667 & 13334 \\
\hline
\end{tabular}

Figure 3 is a graphical representation of model movements of the Ram shifting from lower position (l.p.) to upper position (u.p.) by rocket engines, and its shifting from upper position (u.p.) to lower position (l.p.) again by rocket engines, their tractions being equal.

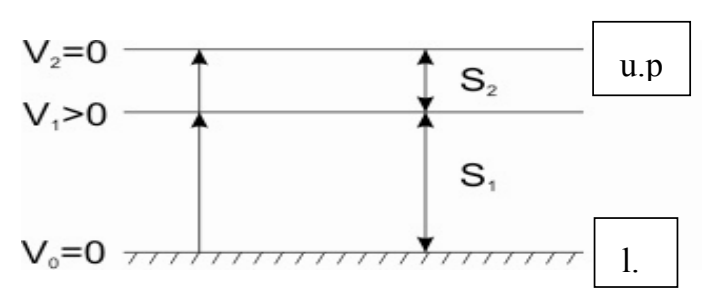

a

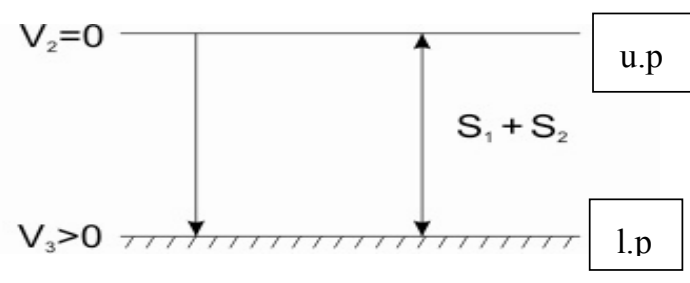

$\mathrm{b}$

Figure 3. Movement of a pile driving hammer Ram actuated by rocket engines:

a - shifting of the Ram from the lower position (1.p.) to the upper position (u.p.)

$\mathrm{b}$ - shifting of the Ram from the upper position (u.p.) to the lower position (1.p.)

Symbols on the Figure 3:

$\mathrm{V}_{0}$ - initial velocity of the Ram,

$\mathrm{V}_{1}$ - velocity of the Ram after covering the distance $\mathrm{S}_{1}$, from lower position (1.p.) by an operating rocket engine,

$\mathrm{V}_{2}$ - velocity of the Ram after covering the distance $\mathrm{S}_{2}$, to upper position (u.p.) with switched off non-operating engine, i.e. by inertia,

$V_{3}$ - velocity of the Ram after covering the distance $S_{1+2}=S_{1}+S_{2}$, from upper position (u.p.) to lower position (1.p.) - with an operating engine.

For the velocities specified above we have: $V_{0}=0, V_{1}>0, V_{2}=0$ and $V_{3}>0$. Times for covering distances $S_{1}, S_{2}$ and $S_{1+2}$, from the lower position (l.p.) to the upper position (u.p.) are respectively $t_{1}, t_{2}$ and $t_{1+2}$. Time for covering 
the distance $\mathrm{S}_{1+2}$ by the Ram from the upper position (u.p.) to the lower position (l.p.) under the action of an operating rocket engine is $t_{3}$. The sum of the times $t_{1+2}$ and $t_{3}$ is indicated with $t_{1+2+3}$.

In a nutshell, the movements of the hammer Ram are the following:

1) switching on the rocket engine 4 for raising the Ram and covering the distance $S_{1}$ with an operating engine, where its velocity reaches $\mathrm{V}_{1}>0$,

2) switching off the rocket engine 4 and covering the distance $S_{2}$ by inertia, where its velocity reduces to $V_{2}=0$,

3) switching on the rocket engine 9 for accelerating the Ram - for striking a blow, covering the sum of distances $\mathrm{S}_{1+2}$, till reaching the blow velocity $\mathrm{V}_{3}>0$.

Determination of the movement velocities of the Ram bottom-up and vice versa was made by the means of classical mechanics by using the motion of a material point theorem (Bodurov, 1973; Bodurov \& Radev, 1979). Resistance of the environment, friction in the guides and changes in the mass of the working media (fuel, oxidant etc.) are not taken into consideration in calculations, since we have already proved (Bodurov \& Radev, 1979) that due to the small shifting distances of the Rams their effect is insignificant. It is not rational from a structure point of view to realize hammers with a stroke of the Ram larger than 4-6 m. We obtained the following formula for the final velocity $\mathrm{V}$ of the Ram $\mathrm{G}$ after covering the distance $\mathrm{S}$ under the action of the rocket engine with a constant traction $\mathrm{R}$ and earth acceleration $\mathrm{g}$ :

- at a vertical motion top-down:

$$
V=\sqrt{2 g S\left(\frac{R}{G}+1\right)}
$$

- at a vertical motion bottom-up:

$$
V=\sqrt{2 g S\left(\frac{R}{G}-1\right)}
$$

- at a horizontal motion:

$$
V=\sqrt{2 g S \cdot \frac{R}{G}}
$$

- at a tilt motion top-down (at an angle $\alpha$ above the horizontal)

$$
V=\sqrt{2 g S\left(\frac{R}{G}+\sin \alpha\right)}
$$

- at a tilt motion bottom-up (at an angle $\alpha$ under the horizontal)

$$
V=\sqrt{2 g S\left(\frac{R}{G}-\sin \alpha\right)}
$$

The Table 2 shows calculated parameters of the four variants given in the Table 1. For simplifying the calculations, we ignored the water resistance and friction in the guides during the motion of the Ram. In underwater realization of the hammer it will be necessary to correct, in the tests, the values of tractions of the rocket engines and the times, within several percents, in order to keep the calculated velocities of the Ram during the blow. The Ram will start moving from the point when the traction of the actuating rocket engine reaches a value greater than its weight, so it will be necessary to increase its stroke. This increase will vary from 3 to $20 \%$ - depending on the time of traction growth until it reaches its set value.

It is seen from the Table 2 that the action time of the rocket engines with a traction $\mathrm{R}$, in a motion up and in a motion down, is of the order of magnitude of $1 \mathrm{~s}$, and the duration of one working cycle of the hammer (for shifting in the initial position and striking of one blow) reaches about $2 \mathrm{~s}$. This also determines the performance capacity of the hammer - not less than 30 impacts per minute. The proposed velocities of the Ram are quite common for pressure forging, i.e. metal-working hammers, and they should be no problem also for pile driving, especially if the piles are metal. We believe that it is quite real to use even higher velocities of the Ram for pile fixing, for example reaching about 11-12 $\mathrm{m} / \mathrm{s}$. The piles driven at higher velocities will have a greater bearing capacity. Driving with a complex blow (Bodurov, 1986) will also increase the quality of the hammer operation and its performance capacity. The complex blow is a unique feature of the Ram actuated by a rocket engine because, in addition to its inertial forces, the traction of the rocket engine will also exert pressure at the moment 
of the impact, i.e. we will have a complex blow combining a blow with a pressure force. For such a blow it is sufficient that the rocket engine can continue to act even after the Ram starts the blow and continues its action during the whole duration of the blow. We expect that the real driving when using a complex blow will be more effective than the driving with an ordinary blow, i.e. a blow where only inertial forces of the Ram will act on the driven pile. A rocket hammer will realize an ordinary trouble-free blow as well; for this purpose it is sufficient that its rocket engine ceases functioning before the blow starts. The maximum stroke of the Ram in the examples given is about $2 \mathrm{~m}$. In such a case the largest size of the hammer, for the variant No. 4, will be about $5 \mathrm{~m}$. The lack of hermetization case of the Ram, isolating from the contact with water, will lead to reduction of the total mass of the hammer. We assume that the total mass of the hammer will be by $20-25 \%$ greater than the mass of the Ram.

Table 2

\begin{tabular}{llllllllllll}
\hline № & $\mathrm{R}$ & $\mathrm{S} 1$ & $\mathrm{~V} 1$ & $\mathrm{t} 1$ & $\mathrm{~S} 2$ & $\mathrm{t} 2$ & $\begin{array}{l}\mathrm{S} 1+2 \\
{[\mathrm{~m}]}\end{array}$ & $\begin{array}{l}\mathrm{t} 1+2 \\
{[\mathrm{~s}]}\end{array}$ & $\begin{array}{l}\mathrm{V} 3 \\
{[\mathrm{~m} / \mathrm{s}]}\end{array}$ & $\begin{array}{l}\mathrm{t} 3 \\
{[\mathrm{~s}]}\end{array}$ & $\begin{array}{l}\mathrm{t} 1+2+3 \\
{[\mathrm{~s}]}\end{array}$ \\
\hline $\mathbf{1}$ & 30000 & 0,66 & 1,8 & 0,73 & 0,16 & 0,18 & 0,82 & 0,91 & 6,0 & 0,27 & 1,18 \\
$\mathbf{2}$ & 22000 & 0,89 & 2,09 & 0,85 & 0,22 & 0,21 & 1,11 & 1,06 & 7,0 & 0,32 & 1,38 \\
$\mathbf{3}$ & 16875 & 1,17 & 2,4 & 0,97 & 0,29 & 0,24 & 1,46 & 1,21 & 8,0 & 0,36 & 1,57 \\
$\mathbf{4}$ & 13334 & 1,48 & 2,69 & 1,1 & 0,37 & 0,27 & 1,85 & 1,37 & 9,0 & 0,41 & 1,78 \\
\hline
\end{tabular}

The use of additional non-complex structures that could support, during driving and fixing, the hammer and pile at a given angle expands the possibilities of the hammer with an active Ram - it will be possible to drive piles at any angle of the space. This is of great importance because you can use also the possibilities offered by the topography of the basin floor. The piles driven at certain angle will ensure a more reliable and safe anchoring of oil platforms and other facilities. The tilt driving will also allow to use piles with smaller sizes and lower prices. The solution for PDH given here proposes a lot of variants for realization and this is a prerequisite for a settlement of urgent production problems caused during operation of the hammer in various water basins and harsh weather conditions. Applying such a hammer will lead to even greater invasion of the rocket/spacecraft technology into the civic industry. We expect that with its help some important technical and economical problems of the world economy will be solved and, in the first place, assimilation of natural resources locating on the world ocean floor will be accomplished.

\section{Conlusion}

Our experience in developing hammers actuated by rocket engines affords ground to state that the PDH proposed will have the following advantages:

- no practical limitations for realization of desired driving velocities of the Ram,

- no practical limitations for the mass of the Ram,

- no practical limitations for realization of very high impact energies,

- realization of pile driving at a speed higher than that used until now,

- realization of pile driving with a complex (combined) blow,

- realization of a performance capacity higher than that of the existing underwater pile driving hammers,

- no limitations for underwater depths for driving piles in conditions of water basins,

- simple design of the hammer, with a possibility for small sizes, small mass and simplified manufacturing,

- simplified and cheap operation of the hammer in pile driving,

- increased operational reliability,

- possibility for pile driving at any angle in the space,

- universal application of the hammer, 
- no matter if it will work in sweet, salt or other water environment,

- no matter what the basin floor is,

- no matter what the environment temperature is,

- no matter if there are solid particles or other pollution of the environment,

- ensures ecologically friendly operation.

\section{References}

Bodurov, P. (1973). On the possibility for use of rocket engines in high speed hammers. Mashinostroene, 4, 160-162. (in Bulgarian)

Bodurov, P. (1986). Forging Press Machine with Rocket Actuation. Mashinostroene, 5, 207-209. (in Bulgarian)

Bodurov, P. (2008). Device for pile anchoring, BG Patent No. 65 331/2008.

Bodurov, P. et al. (1999). High Speed Hammer. BG Patent No. 62 157/1999.

Bodurov, P., \& Genchev, V. (2011). Pile propelling hammer. BG Patent Application No. 111 092/2011.

Bodurov, P., \& Penchev, T. (2005). Industrial rocket engine and its application for propelling of forging hammers, Journal of Materials Processing Technology, 32, 593-604.

Bodurov, P., \& Radev, S. (1979). Speed possibilities of a High Speed Hammer with rocket Engine. Scientific Papers of VIMMESS Institute of Rousse, XXI, 4, 1979, 225-228 (in Bulgarian).

MENCK. (1994). Offshore Hydraulic Pile Driving Hammers MHU, 5/1994.

P. Bodurov. (1978). High Speed Hammer. BG Patent No. 24 567/1978.

Raketenantrieb für Schmiede-und Rammhämmer. (2009). UMFORM Technik, 2.2009, June, 34. 